\title{
Urinary Tract Infections in Patients Admitted to the Nephrology Department
}

\author{
Mouayche Ikhlas ${ }^{1, ~ *, ~ H a m d a n i ~ H a n a ~}{ }^{1}$, Hiddou Abdesalam ${ }^{1}$, El Assas Hajar ${ }^{2}$, Fadili Wafaa ${ }^{2}$, \\ Laouad Inass ${ }^{2}$, Soraa Nabila ${ }^{1}$ \\ ${ }^{1}$ Departement of Bacteriology and Virology, University of Medicine and Pharmacy, Marrakech, Morocco \\ ${ }^{2}$ Departement of Nephrology and Hemodialysis, University of Medicine and Pharmacy, Marrakech, Morocco \\ Email address: \\ I.Mouayche@gmail.com (M. Ikhlas) \\ ${ }^{*}$ Corresponding author
}

\section{To cite this article:}

Mouayche Ikhlas, Hamdani Hana, Hiddou Abdesalam, El Assas Hajar, Fadili Wafaa, Laouad Inass, Soraa Nabila. Urinary Tract Infections in Patients Admitted to the Nephrology Department. International Journal of Infectious Diseases and Therapy.

Vol. 3, No. 2, 2018, pp. 34-39. doi: 10.11648/j.ijidt.20180302.13

Received: May 15, 2018; Accepted: May 29, 2018; Published: August 1, 2018

\begin{abstract}
Urinary infections (UI) remain among the most frequent problems faced by the clinician and occupy a prominent place in nephrological pathology due to their frequency and severity. The aim of this work is to study the aspect of UI in the nephrology service. Materials and methods: This is a prospective study over a periodof 5 months (July 2016 - December 2016). Results: 115 patients had benefited from cytobacterioligical urine exam. The prevalence of UI was $31 \%$. The mean age of patients was 38 years with a female predominance. Renal failure was found in 33\% of patients followedby nephrotic syndrome (25\%) and kidney transplant (11\%). Chronic renal insufficiency was foundin $25 \%$ of patients and $23 \%$ receivedan Endoxanbolus. The mostincri minatedspecies were Enterobacteriae ( $81 \%$ ) with the predominance of E. coli ( $44 \%)$ followed by Klebsiella pneumoniae (31\%) Enterobacter cloacae (3\%) resistance to C3G by production of Betalactamases with extended spectrum was found in $24 \%$ of Enterobacteriaceae. Resistance to amoxicillin-clavulanic acidwas $72 \%$, fluoroquinolones (34\%) and gentamicin (14\%). Thefirst-lineantibioticwas Ciprofloxacinin (62\%) and a third generation cephalosporin in $28 \%$ of cases. Conclusion: Area soned use of antibiotic sisnecessaryin order to prevent the extension of bacterial resistance.
\end{abstract}

Keywords: Urinary Infection, Kidney Failure, Enterobacteriaceae, Antibiotic Resistance, E. coli, Ciprofloxacin

\section{Introduction}

Urinary tract infections are a real public health problem. The increasing antibiotic resistance of the bacteria involved in UI limits the choice of antibiotics and warrants surveillance.

The annual incidence of urinary tract infections is estimated in the United States at 11 million cases and in France at 4-6 million cases $[1,2]$. In Morocco, urinary tract infections remain frequent and rank first in hospitals. In nephrology, urinary tract infection is a frequent reason for consultation and is present in a large number of hospitalized patients [3]. Very few studies are available on this topic. Urinary tract infection in patients with renal insufficiency is a complicated urinary tract infection requiring special diagnostic and therapeutic management $[4,5]$. It is a frequent but serious pathology because grafted of a heavy morbimortality [6]. The bacteriological samples are precious, indispensable and allow to establish a suitable treatment.

These urinary infections, at the origin of many prescriptions of antibiotics, participate in the pressure of selection of bacterial resistance to antibiotics. As such, we undertook this work whose objective is to study the epidemiological, clinical, bacteriological and therapeutic profile of the urinary tract infection in hospitalized patients in the nephrology department of Mohamed VI University Hospital of Marrakech.

\section{Materials and Methods}

This is a prospective observational and descriptive study over a 5-month period from July 2016 to December 2016 and 
includes all the ECBUs systematically performed on all patients hospitalized in the nephrology department and treated at the laboratory level. Microbiology of Mohammed VI University Hospital of Marrakech.

The data were collected from the medical records of hospitalized patients in the nephrology department and from the database of the microbiology laboratory of the Mohamed VI University Hospital. These data were entered on a record that included anamnestic, clinical, bacteriological and therapeutic variables.

The positive diagnosis of urinary infection was established on the data of the cytobacteriological examination of the urine. Each urinary specimen sent to the laboratory was subjected to a cytobacteriological urinalysis including:

(1) uroculture with enumeration of bacteria (bacteriuria);

(2) a microscopic examination to assess leukocyturia and other elements of the urine (red blood cells, crystals, yeasts, etc.).

Included in this study were urinary specimens meeting IU criteria with leukocyturia greater than $104 / \mathrm{ml}$ and a bacterial mono culture considered significant. The threshold of bacteriuria was interpreted according to bacterial species, sex and clinical context. The bacteriuria thresholds of 103 CFU/ $\mathrm{ml}$ were retained for urinary E. coli infections and a threshold of $104 \mathrm{CFU} / \mathrm{ml}$ was retained for Enterobacteriaceae more commonly involved in the setting of nosocomial urinary infections. The identification of bacteria was made on conventional morphological, cultural and biochemical characters. The study of antibiotic susceptibility was carried out according to the technique of diffusion of disks in agar medium and the interpretation was made according to the standards of the Committee of the antibiogram of the French Society of Microbiology (CA-SFM). broad-spectrum betalactamase (ESBL) producers were systematically detected by the synergy test between a central disk of amoxicillin + clavulanic acid and beta-lactam disks (cefotaxime, ceftazidime, cefepime and aztreonam). The presence of ESBL was noted in front of a "champagne cork" appearance.

\section{Results}

During the study period, 115 patients received ECBU. The prevalence of urinary tract infection was $31 \% .15 \%$ had significant leucocytury with a polymicrobial culture. The median age was 38 years old. $55.6 \%$ were female. Renal failure was found in 33\% of patients followed by nephrotic syndrome $(25 \%)$ and renal transplant recipients $(11 \%)$. Chronic renal failure was found in $25 \%$ of patients and $23 \%$ benefited from an Endoxan bolus. Figure 1 shows the distribution of IUs documented by reason of hospitalization.

Clinical signs indicative of UTI were very polymorphic dominated by micturition (18.3\%) followed by fever $(14 \%)$ and lumbar pain (10\%). The most common clinical forms were asymptomatic bacteriuria (46.7\%), cystitis $(30.6 \%)$ and acute pyelonephritis (PNA).

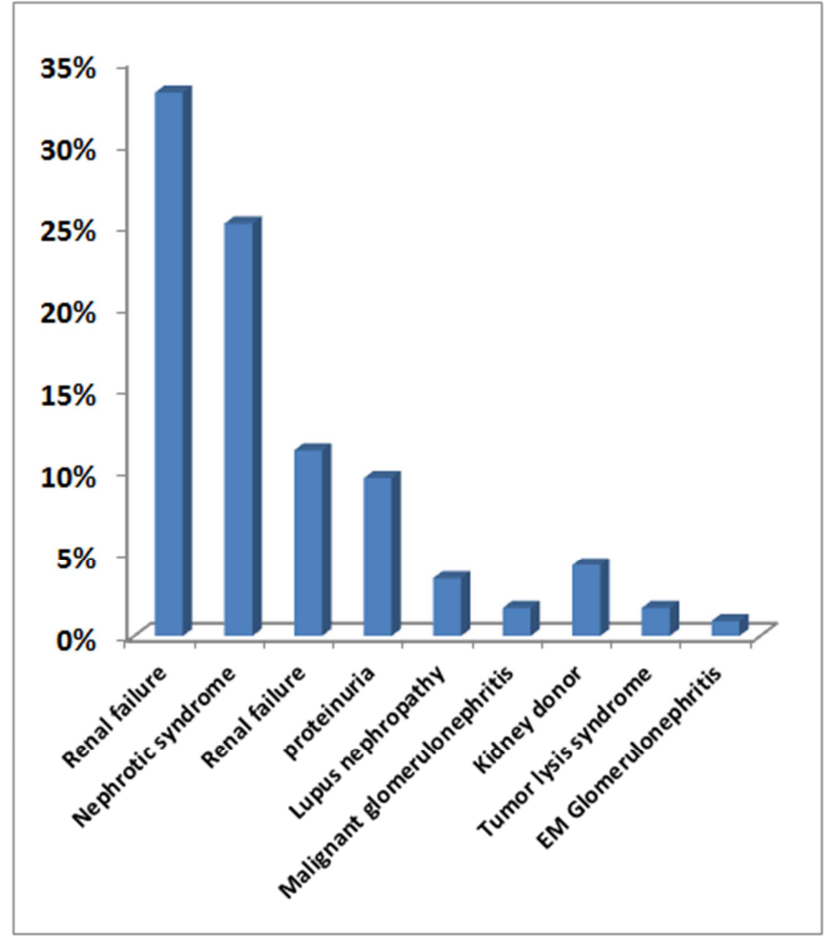

Figure 1. Distribution of IUs documented by reason of hospitalization in nephrology.

The appearance of ECBU was clear in $41 \%$ of cases, trouble in $(29 \%)$ and slightly troublein $(22 \%)$. Hematuria was present in $81 \%$ and leukocyturia in $65 \%$ of cases. For completed ECBUs, $31 \%$ met the infection criteria positifs, $28 \%$ had no criteria for urinary tract infection, germ-free leukocyturia in culture was found in $26 \%$ of cases and $15 \%$ were polymicrobial. Figure 2 shows the distribution of ECBUs produced during this period according to crop results.

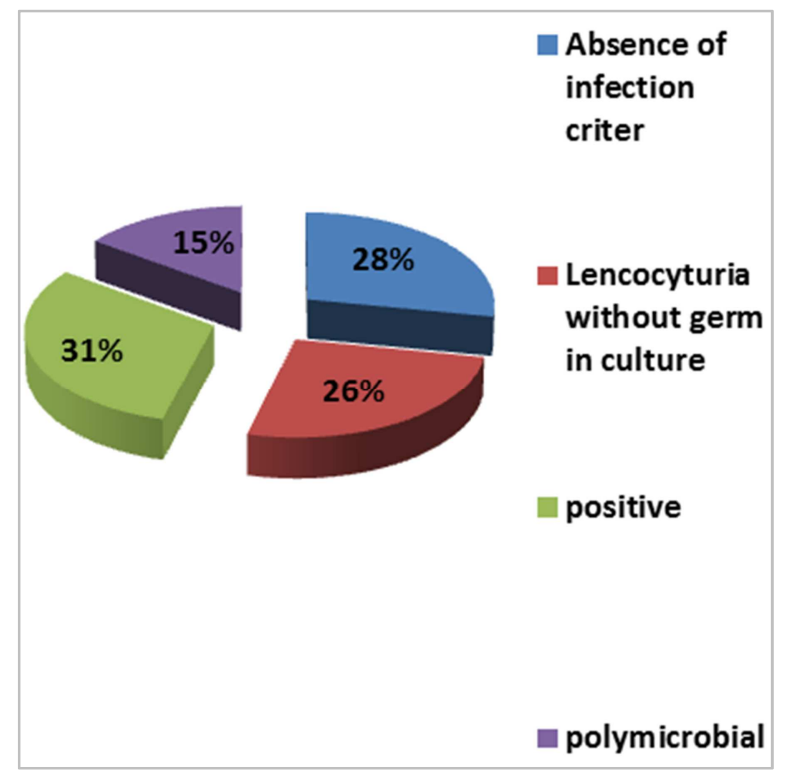

Figure 2. Distribution of ECBUs in Nephrology Patients by Cultures Results. 
The most incriminated species were enterobacteria (81\%) with the predominance of Escherichia coli (44\%) followed by Klebsiella pneumoniae (31\%) and Enterobacter cloacae $(3 \%)$. The resistance of enterobacteria to amoxicillinclavulanic acid was $83 \%$.

Table 1. Percentage of resistance to antibiotics of uropathogenic enterobacteria $(n=29)$.

\begin{tabular}{ll}
\hline Antibiotics tested & Percentage of resistance \\
\hline Amoxicilline & $83 \%$ \\
Amoxicilline+Acide clavulanique & $72 \%$ \\
C3G & $24 \%$ \\
Ciprofloxacine & $34 \%$ \\
Cotrimoxazole & $67 \%$ \\
Gentamicine & $14 \%$ \\
Amikacine & $3 \%$ \\
\hline
\end{tabular}

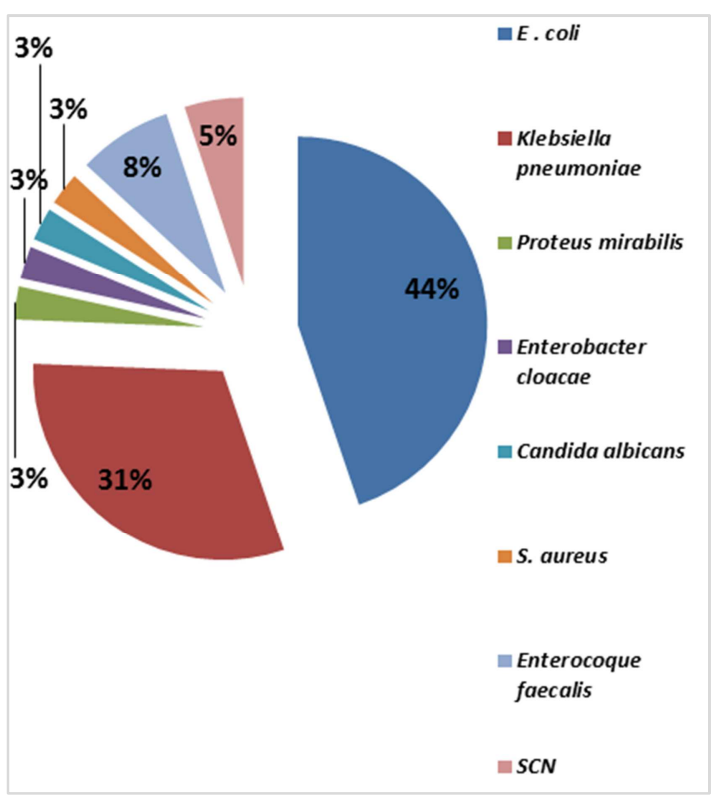

Figure 3. Distribution of uropathogenic bacteria in hospitalized nephrology patients $(n=115)$.

Table 2. Percentage of antibiotic resistance of the enterobacteriaceae isolated in IU in Nephrology.

\begin{tabular}{|c|c|c|c|c|c|c|c|c|}
\hline Enterobacteriaceae & AMX & AMC & IMP & C3G & CIPRO & SXT & GENTA & AMIKA \\
\hline E.coli & $69 \%$ & $63 \%$ & $6 \%$ & $19 \%$ & $44 \%$ & $63 \%$ & $6 \%$ & $6 \%$ \\
\hline K. pneumoniae & $100 \%$ & $82 \%$ & $18 \%$ & $36 \%$ & $27 \%$ & $78 \%$ & $27 \%$ & $0 \%$ \\
\hline E. cloacae & $100 \%$ & $100 \%$ & $0 \%$ & $0 \%$ & $0 \%$ & $0 \%$ & $0 \%$ & $0 \%$ \\
\hline Proteus mirabilis & $100 \%$ & $100 \%$ & $0 \%$ & $0 \%$ & $0 \%$ & $100 \%$ & $0 \%$ & $0 \%$ \\
\hline
\end{tabular}

AMX: amoxicillin; AMC: amoxicillin-clavulanic acid; C3G: 3rd generation cephalosporin; CIPRO: ciprofloxacin; SXT: sulfamethoxazole-trimethoprim; GENTA: gentamicin; AMIKA: amikacin; IMP: imipenem.

Resistance to $\mathrm{C} 3 \mathrm{G}$ by ESBL production was found in $24 \%$ of isolated enterobacteria. Among the uropathogenic Enterobacteriaceae in nephrology, the carbapenem-reduced susceptibility strains represented $10 \%$ mainly affecting Klebsiella pneumoniae and Enterobacter cloacae. Figure 3 illustrates the distribution of uropathogenic bacteria in hospitalized patients in the nephrology department.

Resistance to fluoroquinolones was found in 34\% of isolates and gentamicin in $14 \%$. Table I reports the antibiotic resistance rate of the main isolated enterobacteria.

The antibiotic prescribed as first-line was ciprofloxacin in $62 \%$ cases and a third generation cephalosporin in $28 \%$ of cases.

The evolution was favorable in $90 \%$ of the cases. $6 \%$ had sepsis and one death was recorded in $4 \%$ of patients.

\section{Discussion}

The urinary tract infection has been the subject of numerous studies because of its frequency and etiological and evolutionary seriousness, motivating prescriptions of antibiotics most often its profile vis-à-vis antibiotics [7]. In this context, the urinary tract infection has often been without bacteriological documentation immediately complicated and requires an early diagnosis and accurate and appropriate care. It can lead to general complications, such as urinary bacteremia [8].

Most epidemiological studies [9-10] have shown that urinary tract infection is more common in women than in men. In this study, a female predominance was found with a sex ratio $\mathrm{H} / \mathrm{F}$ of 0.8 due to anatomical and physiological peculiarities in women.

The average age of 38 years is similar to that reported by a retrospective study that included 145 cases collected in the nephrology department of Ibn Rochd University Hospital in Casablanca (35 years) [3].

This study showed that the prevalence of urinary nephrology infection was high. It was of the order of $31 \%$ as demonstrated by many studies $[3,18]$.

The location of UI in nephrology patients was unique, with 1 in 4 patients in CKD receiving immunosuppression. 20\% of the patients were hypertensive and $6 \%$ were diabetic. In Casablanca, Bourquia et al. [3] reported $6.2 \%$ of diabetes; $1.37 \%$ of corticosteroids in the IU of the patient in Nephrology.

The frequency of CKD in this study was similar to that found by CHEMLAL et al. [18] (25\%) and lower than TRAORE et al. [17] (49\%); this is explained by the everincreasing frequency of CKD causes, namely hypertension and diabetes in the general population.

Diabetes is a factor favoring urinary tract infection. The frequency of diabetes in this study is close to that found by 
TRAORE et al. [17] (10\%) and low compared to CHEMLAL et al. [18] (35.4\%).

Burnout (18.3\%), fever (14\%), lumbar pain $(10 \%)$ and dysuria $(9 \%)$ were the main manifestations of symptomatic urinary tract infection. In Bamako TRAORE et al. [17] found $58.7 \%$ of vomiting, $46.7 \%$ of fever, $15.8 \%$ of lumbar pain and $11.9 \%$ of micturition.

In Casablanca Bourquia et al. [3] report a prevalence of micturition $(57 \%)$ and lumbar pain $(41 \%)$. The frequency of micturition and lumbar pain in this study were close to those found by TRAORE et al. And too low compared to the casablanca study.

Leukocyturia may be absent in 20 to $40 \%$ of cases [20]. Isolated bacteriuria that reaches significant values should always point to a urinary tract infection. Indeed, although there are quite close correlations between bacteriuria and leukocyturia, discrepancies between these two data can be seen especially in diabetic subjects and in pregnant women.

Microscopically, leukocyturia was present in 75 cases (65\%), microscopic hematuria in $81 \%$ and bacteriuria $(52 \%)$.

According to a national study, the authors report $80-90 \%$ leukocyturia, $45 \%$ hematuria and $72.41 \%$ bacteriuria [3].

The nature of the isolated germs varies according to the studies. In a prospective study started from (2012 to 2014) conducted at the Nephrology Department at the Oujda Regional Hospital, the isolated germ was an E. coli in 58.3\% and Klebsiella in $29.2 \%$. Candida albicans was associated in $4.2 \%$ of cases. $16.7 \%$ of the bacteria were resistant to $\mathrm{C} 3 \mathrm{G}$ by ESBL production [18]. According to another study conducted in the nephrology department of CHU ibn Rochd, the most frequently found organisms were enterobacteria in $61 \%$ of cases, with the predominance of E. Coli $(28 \%)$, followed by Klebsiella (17\%) and Proteus (6\%) [3].

Moreover, in this series, enterobacteria dominated the profile of uropathogenic germs with the predominance of $\mathrm{E}$. Coli followed by Klebsiella pneumonia and Enterobacter cloacae which joins the epidemiology of urinary tract infection in children and adults in the literature.

The study of the susceptibility of enterobacteria to antibiotics revealed an increase in the level of resistance for the majority of the antibiotics tested. This finding, reported also by various studies in particular, a prospective study at the Oujda hospital. Indeed, the authors included in this study all patients hospitalized in the nephrology department, with renal impairment defined by a glomerular filtration rate $<60$ $\mathrm{ml} / \mathrm{min} / \mathrm{m} 2$ and/ or chronic hemodialysis and presenting a documented urinary tract infection. Isolated enterobacteria were resistant to amoxicillin-clavulanic acid in $83 \%$ of cases, cephalosporin of third generation in $25.5 \%$ and quinolones in $29.8 \%$ [18].

This increase in the resistance found and the consequence of the pressure of selection due to the massive prescription and the often abusive use of the antibiotics with broad spectral as well in hospital environment as in community, as well as cross-transmission of acquired resistances with plasmid determinism. The resistance of E. Coli vis-à-vis the majority of ATB has increased in a way progressive.

This increase was more marked for laiprofloxacin (44\%) and the sulfamethoxazole + trimethoprim combination (63\%). This is close to the European data which showed that the sensitivity of E. Antibiotic E. coli has declined steadily over the last decade in many countries [19]. This surveillance confirms the worrying nature of the evolution of $E$ resistance. Coli with fluoroquinolones.

This study showed high but relatively stable resistance levels for amoxicillin, amoxicillin-clavulanic acid, and sulfamethoxazole + trimethoprim. This is probably due to a large prescription by our doctors strongly limiting their interest in probabilistic treatment of UI. These results are consistent with other Tunisian [30] and European studies [23].

In this study, resistance to $\mathrm{C} 3 \mathrm{G}$ by ESBL production was found in $24 \%$ of isolated enterobacteria, close to literature data. The problem related to the production of an ESBL is especially the frequent presence of co-resistances making the multi-resistant strains with great power of dissemination.

In this study, amikacin remains the most active molecule, which is consistent with results found in New zealand [21]. FQ and the combination sulfamethoxazole + trimethoprim were the molecules most affected by résistance.

Table 3. Comparison of the percentages of resistance of E. coli Antibiotic according to studies in nephrology patients.

\begin{tabular}{llll}
\hline Study & Ampicilline & Céphalosporin 3rd génération & Ciprofloxacine \\
\hline Our series (16) & 69 & 19 & 44 \\
Oujda(28) & 75 & 17.85 & 28.57 \\
Tunisie (20) & 68 & 6.2 & 9 \\
Turquie (25) & 73.3 & - & 12 \\
USA (26) & 39.3 & - & 6.8 \\
Russie (27) & 37.1 & - & 4.5 \\
Canada (26) & 33 & - & 1.1 \\
\hline
\end{tabular}

As a result, the frequent use of carbapenems to treat $\mathrm{C} 3 \mathrm{G}$ resistant enterobacterial infections has led to the emergence of carbapenemase-producing enterobacteria with the risk of therapeutic impasse and with all the ecological and infectious consequences that this may have.

The emergence of multi-resistant urinary germs is a big problem in everyday practice. It is at the origin of the prolongation of the duration of hospitalization and consequently of a morbidity more important. The emergence of resistance is intimately linked to previous contact with antibiotics, hospitalizations, prolonged antibiotic therapy, sometimes unjustified, and abusive antibiotic prophylaxis. The fight against this phenomenon requires compliance with rules of antibiotic prescription, respect for asymptomatic 
bacteriuria and the implementation of a policy of antibiotic therapy [13-14].

Antibiotic susceptibility of incriminated organisms, especially Enterobacteriaceae, is declining steadily throughout the world, but with differences between series. We compared our data with the literature to look for a difference between regions. Table III reports the resistance of E. coli. antibiotic coli according to different studies) $[15,16]$. Differences in sensitivity are due to selection pressure due to the frequent use of antibiotics The clinic and the simple biological examinations are often sufficient for the diagnosis of localization. In this series, cystitis is dominated profile (31\%) and pyelonephritis in $22.5 \%$ of cases. These percentages are also found in a study conducted in the nephrology department of CHU ibn Rochd [3], where the isolated IU was found in $45 \%$ of cases, cystitis $(25 \%)$ and Pyelonephritis $(20 \%)$. with a predominance for the young adult. The female sex was the most affected. Cystitis was the most observed clinical form.

The epidemiology of uropathogenic germs did not show any particularities in the patient in nephrology. The problem of resistance was posed in enterobacteria with $24 \% \mathrm{C} 3 \mathrm{G}$ resistance and $10 \%$ carbapenem-reduced susceptibility strains in ESBL-producing strains of Klebsiella pneumoniae and Enterobacter cloacae. Faced with this increase in the frequency of antibiotic resistance in uropathogenic enterobacteria, the hospital should take a number of steps to prevent the spread of multidrug-resistant enterobacteria. This prevention requires the strengthening of hospital hygiene measures, the rational prescription of antibiotics guided by the results of the antibiogram, the screening and the technical and geographical isolation of patients with multidrugresistant bacteria.

\section{Conclusion}

Urinary tract infection is the most common bacterial infectious pathology in the general population, including in patients with renal insufficiency. The main issue in patients with renal insufficiency is the adaptation of the dosages of antibiotic treatments. The best treatment is prevention by early detection of urinary tract infections and adherence to good antibiotic prescribing practices. Controlling bacterial resistance to antibiotics is a public health priority that requires concerted action in health and research institutions. Prevention of crosstransmission and reduction of selection pressure by rational use of antibiotics are two essential components.

\section{References}

[1] Nielubowicz G, Mobley H. Host-pathogen interactions in urinary tract infection. Nat RevUrol. 2010 Aug; 7 (8): 430-41.

[2] Elkharrat D, Arrouy L. Épidémiologie de l'infection urinaire communautaire de l'adulte en France; Les infections urinaires. Monographies en urologie. 2007; 1-20.

[3] BOURQUiA A, RAMDANI B, SAHNI K, ZAID D. Profil de l'infection urinaire dans un service de néphrologie. Médecine du Maghreb. 1992; 33: 11-16.

[4] Infections urinaires de l'adulte et de l'enfant, les recommandations 2008 de l'AFSSAPS.

[5] Ponte B, Saudan P. L'insuffisance rénale aigüe en 2008. Revue médicale suisse. Number 3147.

[6] Uchino S, et al. Acute renal failure in critically ill patients- a multinational, multicenter study. JAMA. 2005 Aug 17; 294 (7): $813-818$.

[7] LOBEL B. Traitement de la cystite chez la femme. Presse Med. 1995; 24(32): 1527-9.

[8] BENNSMAN A. Infection de l'appareil urinaire chez l'enfant. Meyrier Alain des infections de l'appareil urinaire préface du Pr. François Vachon. Editions médicales de Merck Sharp et Dohme-Chibret 2016.

[9] DUPONT B, FAUCHER JL. Médical aspects of urinary tract infections. J Urol (Paris). 1983; 89 (5): 299-307.

[10] WAGENLEHNE FME, NABER KG. Uncomplicatedurinary tract infections in women. Current Opin Urol. $2001 \mathrm{Jan}$; 11 (1): 49-53.

[11] SQUALLI M, EL MDAGHRI N, BENBACHIR $M$. Diagnostic bactériologique des infections urinaires. Rev Maroc Santé. 1984; 6:3 - 4.

[12] Rim A, Badreddine K, Fakher K. Infections urinaires hautes de l'adulte: à propos de 261 épisodes. La tunisie Médicale. 2010; 88 (9): 629 - 633.

[13] Wagenlehner FME, Wieder W, Naber KG. Emergence of antibiotic resistance among hospital-acquire durinary tract infections and pharmacokinetic/pharmacodynamic considerations. J Hosp Infect. 2005 Jul; 60 (3):191-200.

[14] Stapleton Ann. Urinary tract infections in patients with diabetes. Am J Med. 2002; 113 suppl 1A (8):80-84.

[15] Leonid S, Vladimir V. Antimicrobial susceptibility of pathogens isolated from adult patients with uncomplicated community-acquire durinary tract infections in the Russian federation: two multicentre studies, UTIAP-1 and UTIAP-2. Int J Antimicrob Agents. 2006 Aug; 28 (Suppl 1):S4-S9.

[16] Tsai-Ling Lauderdale, Clifford McDonald L, Yih-Ru Shiau and al. The status of antimicrobialresistance in Taiwan among Gram-negative pathogens: the Taiwan surveillance of antimicribial resistance (TSAR) program, 2000. Diag Micro biol Infect Dis. 2004; 48 (3):211-219.

[17] TRAORE H. Les infections urinaires dans le service de néphrologie et d'hémodialyse de l'hôpital du point $\mathrm{G}$. These Med, Bamako, 2016.

[18] Abdeljalil Chemlal, Fatiha Alaoui Ismaili, Ilham Karimi, RymeElharraqui, Nawal Benabdellah, Samira Bekaoui, Intissar Haddiya, Yassamine Bentata. Les infections urinaires chez les patients insuffisants rénaux chroniques hospitalisés au service de néphrologie: profil bactériologique et facteurs de risque. The Pan African Medical Journal 2015- ISSN 1937-8688.

[19] Elbouamri, L. Arsalane, Y. Kamouni, H. Yahyaoui, N. Bennouar, M. Berraha, S. Zouhair. Profil actuel de résistance aux antibiotiques des souches d'Escherichia coli uropathogènes et conséquences thérapeutiques. Prog Urol, 2014, 24, 16, 1058-1062 
[20] MATHIEU H. Infection urinaire et pathologie du tissu interstitiel. Néphrologie pédiatrique. Flammarion Paris 1983.

[21] De Mouy D, Fabre R, Cavallo JD, Arzouni JP, Baynat M, Bicart-See A, et al. Infections urinaires communautaires de la femme de 15 à 65 ans: sensibilité aux antibiotiques de $E$. Coli en fonction des antécédents: etude AFORCOPI-BIO 2003. Med Mal Infect 2007;37:594-8.

[22] Bénédicte Sautenet, Christelle Barbet, Mathias Büchler, Franck Bruyère. Infections urinaires et antibiothérapie chez l'insuffisant rénal. Vol. 20 Septembre $2010 \mathrm{~N}^{\circ} 3$ Progrès en Urologie.

[23] Kahlmeter G, Poulsen HO. Antimicrobial susceptibility of Escheri-chia coli from community-acquire durinary tract infections in Europe: The ECO. SENS study revisited. Int J Antimicrob Agents 2012; 39:45-51.

[24] LASFARGUES G., ROY C., MONGENOT B. Infections urinaires et pyélonéphrites chroniques bactériennes chezL'enfant. Encyclopédie Médico-chirurgicale 4085 C - 2, 1976.

[25] MADELENAT P, LORGERON P. Infection urinaire gravidique. Revue du Praticien. Tome XXXIV - $\mathrm{N}^{\circ} 18,25$ Mars 1984.
[26] Chantal Bertholom. Épidémiologie des infections urinaires communautaires et nosocomiales. Option/Bio, Volume 27, Issues 541-542, April 2016, Pages 23-24.

[27] BOURRQUELOT P., GUIBERT J. Le traitement médical de l'infection urinaire. Gaz. Med de France - 87 n 13 du 4. IV 1980.

[28] Parvine Tashk, Marie Lecronier, Olivier Clermont, Aurélie Renvoisé, Jérôme Tourret. Épidémiologie moléculaire et cinétique des infections urinaires précoces à Escherichia coli chez les sujets transplantés d'un rein. Néphrologie \& Thérapeutique, Volume 13, Issue 4, June 2017, Pages 236-244

[29] LASFARGUES G., ROY C., MONGENOT B. Infections urinaires et pyélonéphrites chroniques bactériennes chez L'enfant. Encyclopédie Médico-chirurgicale 4085 C - 2, 2012.

[30] Ben Haj Khalifa A, Khedher M. Fréquence et résistance aux antibiotiques des bactéries uropathogènes à l'Hôpital Universitaire Tahar Sfar de Mahdia. RevTun Infect 2010;4(3):92-5. 